\title{
Hemodynamics After Fontan Procedure are Determined by Patient Characteristics and Anastomosis Placement Not Graft Selection: a Patient-Specific Multiscale Computational Study
}

\author{
Authors \\ Ethan Kung $\mathrm{PhD}^{1}$; Catriona Baker MBBS²; Chiara Corsini $\mathrm{PhD}^{3}$; Alessia Baretta $\mathrm{MS}^{3}$; \\ Giovanni Biglino $\mathrm{PhD}^{2}$; Gregory Arbia $\mathrm{PhD}^{4}$; Sanjay Pant $\mathrm{PhD}^{5}$; Alison Marsden \\ $\mathrm{PhD}^{6}$; Andrew Taylor MD2; Michael Quail MBBS²; Irene Vignon-Clementel $\mathrm{PhD}^{4}$; \\ Giancarlo Pennati $\mathrm{PhD}^{3}$; Francesco Migliavacca $\mathrm{PhD}^{3}$; Silvia Schievano $\mathrm{PhD}^{2}$; \\ Anthony Hlavacek MD7; Adam Dorfman $\mathrm{MD}^{8}$, Tain-Yen Hsia MD9; and Richard \\ Figliola $\mathrm{PhD}^{1}$; Modeling of Congenital Hearts Alliance (MOCHA)+ Investigators; \\ ${ }^{1}$ Departments of Mechanical Engineering, Department of Bioengineering, Clemson \\ University, Clemson, SC \\ ${ }^{2}$ Cardiorespiratory Unit, UCL Institute of Cardiovascular Science and Great Ormond \\ Street Hospital NHS Foundation Trust, London, UK \\ ${ }^{3}$ Laboratory of Biological Structure Mechanics, Department of Chemistry, Materials \\ and Chemical Engineering 'Giulio Natta', Politecnico di Milano, Piazza Leonardo da \\ Vinci, 32, 20133, Milano, Italy \\ ${ }^{4}$ INRIA Paris, France \\ ${ }^{5}$ Faculty of Science and Engineering, Swansea University \\ ${ }^{6}$ Departments of Pediatrics (Cardiology) and Bioengineering, Stanford University, \\ Stanford, CA 94305, USA \\ ${ }^{7}$ Division of Pediatric Cardiology, Department of Pediatrics, Medical University of \\ South Carolina, Charleston, SC 29425, USA \\ ${ }^{8}$ Division of Pediatric Cardiology, University of Michigan Medical School, Ann Arbor, \\ MI, USA \\ ${ }^{9}$ Pediatric Cardiac Surgery, Arnold Palmer Hospital for Children, Orlando, FL, USA
}

\section{Correspondence}

Ethan Kung, PhD

ekung@clemson.edu

\section{Conflict of Interest Statement}

There are no conflicts of interest associated with this work.

\section{Acknowledgements}

This work was supported by the Leducq Foundation through a Transatlantic Network of Excellence Program grant, the National Institute of Health Research Biomedical 
medRxiv preprint doi: https://doi.org/10.1101/2021.10.03.21264033; this version posted October 4, 2021. The copyright holder for this preprint

(which was not certified by peer review) is the author/funder, who has granted medRxiv a license to display the preprint in perpetuity.

All rights reserved. No reuse allowed without permission.

Research Centre Funding Scheme, a Burroughs Wellcome Fund Career award at the Scientific Interface, an American Heart Association Postdoctoral Fellowship, NSF CAREER OCl-1150184, and a British Heart Foundation Clinical Research Fellowship FS/12/35/29566. We also acknowledge Dr. Charles Taylor, Dr. Nathan Wilson, Mahdi Esmaily, and Weiguang Yang for their contributions to codes used in the simulations and analyses, and the open source Simvascular project at simtk.org.

This report is independent research by the National Institute for Health Research Biomedical Research Centre Funding Scheme. The views expressed in this publication are those of the author(s) and not necessarily those of the NHS, the National Institute for Health Research or the Department of Health.

\section{Abstract}

Objectives: Patient-specific multiscale modeling simulates virtual surgeries of the Fontan procedure using three different graft options. Predictive modeling details postoperative outcomes that can help inform clinical decision support.

Methods: Six patients underwent preoperative cardiac magnetic resonance imaging and catheterization. Virtual surgery is carried out for each patient to test the resulting hemodynamics of three Fontan graft options: ECC, 9mm Y-graft, and 12mm Y-graft.

Results: 1) one-way ANOVA $p>0.998$ in all systemic pressures and flows between graft options, 2) $p=0.706$ for hepatic flow distribution between graft options, 3) local power loss differences do not affect the systemic circulation, 4) anastomosis positioning modification of the same Y-graft in the same patient changed left PA hepatic distribution from 0.66 to 0.49

Conclusions: Systemic pressures and blood flow after the Fontan procedure are not affected by graft selection but are well influenced by patient pulmonary vascular impedance. The hepatic distribution can be affected by anastomosis placement.

\section{Ultra-mini abstract}

We present the first case series of patient-specific multiscale modeling of the Fontan procedure. Despite noticeable local power loss differences, graft selection does not affect systemic pressure and flow rates or other clinically relevant quantities. Anastomosis placement can affect hepatic distribution.
Abbreviations
BSA - body surface area
$\mathrm{Cl}$ - cardiac index
CMR - cardiac magnetic resonance imaging
GA - general anaesthetic
$\mathrm{Hb}$ - hemoglobin
HLHS - hypoplastic left heart syndrome
IVC - inferior vena cava 
medRxiv preprint doi: https://doi.org/10.1101/2021.10.03.21264033; this version posted October 4, 2021. The copyright holder for this preprint (which was not certified by peer review) is the author/funder, who has granted medRxiv a license to display the preprint in perpetuity.

All rights reserved. No reuse allowed without permission.

LPA - left pulmonary artery

LPN - lumped parameter network

PAs - pulmonary arteries

PAP - pulmonary artery pressure

PVR - pulmonary vascular resistance

SVC - superior vena cava

TPG - trans-pulmonary gradient 
medRxiv preprint doi: https://doi.org/10.1101/2021.10.03.21264033; this version posted October 4, 2021. The copyright holder for this preprint

(which was not certified by peer review) is the author/funder, who has granted medRxiv a license to display the preprint in perpetuity.

All rights reserved. No reuse allowed without permission.

\section{Introduction}

The staged Fontan procedure remains the common approach to palliate single ventricle circulations. The third stage involves connecting the inferior vena cava and superior vena cava returns to the pulmonary arteries resulting in a pulmonary circulation that is driven by systemic venous pressure only. The most common configuration is the total cavopulmonary connection (TCPC). Although commonly successful in the early to midterm postoperative period, Fontan physiology often worsens as patients mature ${ }^{1-3}$, leading to complications such as arrythmia, proteinlosing enteropathy, ventricular disfunction, thromboembolic events, diminished exercise tolerance, fatigue and palpitations ${ }^{4}$. Chronic venous insufficiency, portal hypertension, and retrograde flow in caval veins, which contribute to liver fibrosis or pleural effusions, are also common clinical morbidities for Fontan patients ${ }^{5}$.

In an effort to improve potential flow imbalances to the right and left pulmonary circulations, a Y-graft design was previously developed to replace the extracardiac conduit (ECC) used in the TCPC ${ }^{6,7}$. The earliest $Y$-graft design was optimized to each patient's specific anatomy and geometry ${ }^{6}$. The latter Y-graft was chosen using commercially available bifurcating grafts ${ }^{7}$. The promise of the $Y$-graft was to reduce power loss, thereby reducing ventricular work, and simultaneously to improve distribution of inferior venous flow, which would balance hepatic factors to the right and left lungs ${ }^{6-8}$. Despite the clinical use of the Y-graft in several studies, it remains unclear to what degree these outcomes are achieved and whether power loss of the surgical junction equates to improved performance of the cavopulmonary circulation ${ }^{9}$.

In this study, we constructed patient-specific multiscale models for a cohort of single-ventricle patients undergoing stage 2 to stage 3 surgery. We compared the influence of two Y-graft designs and a traditional extra-cardiac conduit on postoperative outcomes via computational simulation. Patient-specific clinical data was acquired pre-stage 3 and assimilated into physiologic models for each patient in each computational simulation. Multiscale modeling was then used to perform virtual stage 2-3 conversion to compare the performance of graft types. The outcomes of the simulation provide hemodynamic data that is used to assess the physiological consequences of each of the three graft choices.

\section{Methods}

\section{Patient Selection and Clinical Data}

After institutional review board study approval and informed consent for the use of clinical data, six patients were enrolled prior to their pre-operative clinical investigations for planning TCPC. The review entities were Medical University of South Carolina Institutional Review Board and Great Ormond Street Hospital Institutional Review Board. Full approval was given at the start of the project and was renewed yearly until enrollment was completed. Patients were recruited at the Medical University of South Carolina, Charleston, SC, USA, and Great Ormond Street Hospital, London, UK. The pre-operative clinical presentations of the six patients are reported in Table 1. Pre-operative cardiac magnetic resonance imaging (CMR), cardiac catheterization and echocardiography studies were performed prior to surgery in a similar way done for patients studied in Stage $1-2^{10}$. As in our previous study $^{10}$, pulmonary artery pressure (PAP) was either a direct measurement or an 
estimate from pulmonary venous wedge pressure. In patients $C, E$, and F, PAP was acquired on the left side, with no clinical evidence suggestive of a stenosis or cause for discrepancy between the two pulmonary arteries (PAs). In patients A, B, and D, PAPs were acquired on the left and right sides. Only patient $D$ demonstrated anatomical and pressure indications of a left pulmonary artery (LPA) stenosis. Preoperative echocardiography was performed under GA or sedation. Pulsed wave Doppler traces were acquired in the aorta, SVC, IVC and branch PAs.

Three-dimensional models and virtual surgery

Three-dimensional models of each patients' stage 2 anatomy were reconstructed in a similar way as done for Stage 1 patients ${ }^{10}$. Figure 1 depicts the stage 2 to stage 3 reconstructions for the six patients studied 11,12 . The virtual reconstructed geometry was created following the guidance of a cardiac surgeon, to produce three options of the inferior connections: Y-graft with $12 \mathrm{~mm}$ diameter branches $(Y 12 \mathrm{~mm})^{6}$, Y-graft with $9 \mathrm{~mm}$ diameter branches $(\mathrm{Y} 9 \mathrm{~mm})^{7}$, and extracardiac conduit (ECC). The trunk of the graft connecting to the IVC is $18 \mathrm{~mm}$ in diameter for all three options. These model designs were based on previously published clinical results from two centers, one of which used a hand-constructed custom design to preserve cross-sectional area from trunk to branches ${ }^{6}$, and the other of which used an "off-the-shelf" readily available design that did not require suture lines at the bifurcation?

\section{Multiscale Simulation and Analysis}

Multi-scale models were developed and tuned for each patient based on the patient-specific anatomical and clinical data (Table 2). Each patient was modeled at the age and body surface area (BSA) at the time of their CMR scan since both 3D and flow information is acquired at this time-point. Following our previous work ${ }^{11,13}$, a OD lumped-parameter network (LPN) model of the circulatory system outside of the surgical region, was created and coupled directly to the inflow and outflow passages of the 3D model of the surgical site (Figure 2). Previous work ${ }^{14}$ introduced a method to iteratively tune reduced order (i.e. 3-element Windkessel) representations of the 3D model to match clinical inlet average pressure, inlet average flow and the flow repartition for pulmonary outlets. This was then refined previously ${ }^{10}$ to distinguish between the arterial and venous sides, leading to a 5-element reduced model (Fig S1). At this pre-stage 3 state, flow conservation from clinical data (Table 2) made apparent the presence of collateral vessels that warranted modification of the LPN finally resulting in the model shown in Figure 2. The online supplemental materials detail the inclusion of collaterals in the pulmonary circulation.

Multi-scale simulations of the post-operative scenarios were conducted according to previously validated techniques 11,13,15,16. Briefly, this involves discretizing the 3D virtual surgery geometries into isotropic finite-element meshes with maximum edge size of $0.03 \mathrm{~cm}$ (MESHSIM, Simmetrix Inc., New York) and coupling the 3D Navier-Stokes equations to the OD LPN using Neumann boundary conditions, implicit coupling, and outflow stabilization ${ }^{17}$. Flow and pressure in the 3D and LPN domain were solved using a custom incompressible finite element NavierStokes solver (Simvascular, www.simtk.org), and a $4^{\text {th }}$ order Runge-Kutta algorithm, respectively. Simulation time step size was $1 \mathrm{~ms}$ and $1 \mu \mathrm{s}$ for the 3D and LPN domain, respectively. Flow and pressure coupling between domains occurs at every 
medRxiv preprint doi: https://doi.org/10.1101/2021.10.03.21264033; this version posted October 4, 2021. The copyright holder for this preprint

(which was not certified by peer review) is the author/funder, who has granted medRxiv a license to display the preprint in perpetuity.

All rights reserved. No reuse allowed without permission.

3D-domain time step. Each simulation included 12 cardiac cycles where the last cycle data, by which periodicity had been achieved, was used in the final results analysis. We assume that the walls of the 3D geometrical models are rigid because we do not know the data for the heterogeneous assessment of the wall parameters. Moreover, the anastomosis is stiffened because of sutures.

Power loss was calculated from the simulation results according to our previous publication ${ }^{13}$. Hepatic flow distribution was computed by running an advection solver as a post-processing step. The fluid entering the $3 \mathrm{D}$ domain at the IVC outlet face is prescribed to have an "IVC flow concentration" of 1 ; the advection solver then computes the IVC flow concentration in the entire 3D domain over the cardiac cycle based on flow velocities as the IVC and SVC flows mix. The IVC flow concentration through the left and right PAs is integrated over the cardiac cycle to quantify hepatic flow distribution.

For statistical analyses of the simulation results, we performed one-way ANOVA to quantify the differences between the Fontan graft options. We consider the differences to be statistically insignificant, potentially significant, and significant, when $p>0.95,0.95>p>0.05$, and $p<0.05$, respectively.

\section{Results}

The pre-operative model tuning produced patient-specific results matching clinical data with discrepancies $<3.3 \%$ for all measured parameters except for the left pulmonary flow ratio and the atrial pressure (where the percentage discrepancies are higher due to the parameters' values being very small) (Table 2). Notably, The SVC $(0.7 \sim 1.6 \mathrm{~L} / \mathrm{min})$ and the collateral $(0.4 \sim 1 \mathrm{~L} / \mathrm{min})$ flow rates are greatly different between the patients, with the standard deviation being approximately $30 \%$ of the mean; yet the maximum discrepancy in the tuned model results was only $3.2 \%$ and $2.8 \%$ for each parameter, respectively (Table 2 ).

Differences in local hemodynamics between the different graft options are clearly observed in the predicted post-operative flow outcomes. Using results for Patient $A$ as an example (Figure 3), the ECC typically exhibits a direct encroachment and mixing of blood from the IVC and SVC, where the Y-grafts exhibit the SVC flow impacting the inferior PA wall at the anastomosis and the IVC flow merging into the pulmonary arteries. The smaller diameter Y-graft also exhibits higher flow velocities.

Between the different graft options, there are noticeable differences $(6 \% \sim 32 \%)$ in the surgical junction power loss for each patient. Due to the direct flow encroachment between the IVC and SVC, the ECC consistently (in 5 out of 6 patients) produced higher power loss compared to the Y-grafts. The power loss in the surgical junction typically contributes 10\% 20\% (except in Patient B where it is up to $38 \%$ ) of the power loss in the total pulmonary circulation (Table 3). The magnitudes of these power losses are compared visually in Figure 4, which reveals that in all patients the maximum power loss difference between graft options are very small relative to the total pulmonary power loss. As a result, in each patient there is negligible difference in the ventricular pressure-volume loop and cardiac work between different graft options (Figure 3). Due to the differences in the total 
medRxiv preprint doi: https://doi.org/10.1101/2021.10.03.21264033; this version posted October 4, 2021. The copyright holder for this preprint

(which was not certified by peer review) is the author/funder, who has granted medRxiv a license to display the preprint in perpetuity.

All rights reserved. No reuse allowed without permission.

combined cross-sectional area under an unchanging cardiac output, the wall shear stress varies accordingly between different graft options; and depending on the anastomosis positioning, the wall shear stress can be different between the two legs of the Y-graft (Figure 3).

Statistical analyses revealed insignificant differences between graft options in all physiologic parameters involving pressure and volumetric flow rates (Figure 5). In contrast, there are potentially significant differences in the hepatic flow split between different graft options. This is seen prominently in patient $F$, where the $9 \mathrm{~mm} Y$-graft compared to the ECC produced $61 \%$ versus $28 \%$ hepatic flow entering the LPA, respectively. Furthermore, it is important to note that changing anastomosis positioning of the same graft option on the same patient can directly affect hepatic distribution; For example, two positionings of the same $\mathrm{Y}$-graft in patient $\mathrm{A}$ resulted in $66 \%$ versus $49 \%$ hepatic flow entering the LPA.

\section{Discussion}

Computational investigations of the Fontan palliations have traditionally focused on the power loss of the isolated surgical junctions. Our multi-scale model results show that differences of greater than $30 \%$ in surgical junction power loss still produced negligible effects on most clinically-relevant parameters including cardiac workload and pressure levels in a patient. This finding is consistent with our study on the stage 2 palliation and can be explained by examining the surgical junction power loss in the context of the systemic circuit, an approach possible with our multi-scale computational models. Since much of the power loss of the pulmonary circulation occurs outside of the surgical junction, the patient PVR has a much larger impact on the overall physiology than the hemodynamic differences between different surgical junctions. Figure 4 clearly illustrates that the differences in power loss between different surgical options are very small compared to the total pulmonary power loss in each patient, and thus the impact of graft choice on the overall physiology is minimal. Local flow velocity differences between graft choices, however, may be a consideration factor in term of thrombotic risk. The lower flow velocities in a larger diameter graft may increase thrombotic risk by introducing blood stasis.

Our findings agree with previous single-patient multiscale modeling case studies demonstrating minimal differences in clinically relevant quantifies of interest when changing local geometries in stage 2 and 3 of single ventricle palliation ${ }^{18}$. In particular, similarly small differences in power loss were observed when comparing the hemi-Fontan to bidirectional Glenn surgical choices using multiscale modeling in stage 2 single ventricle patients ${ }^{19}$.

The IVC flow split is an important clinically relevant quantity that is significantly affected by surgical variations. Both graft selection and positioning affect the surgical junction geometry and therefore the resulting IVC flow split. Given the fact that the same graft with different positioning can result in very different IVC flow splits, it is convincing that the actual surgical implementation is the main driving factor in affecting this quantity. Patient-specific multiscale modeling could present considerations for surgical positioning options. 
Prior optimization in idealized Y-graft models also showed large differences in hepatic flow distribution when altering anastomosis location and demonstrated that hepatic flow distribution is primarily dominated by IVC / SVC flow ratio and relative LPA and RPA resistances at the model outlets ${ }^{8,20}$. Additionally, this and other studies have demonstrated that hepatic flow distribution is more robust to geometric variations in the $\mathrm{Y}$-graft designs compared to traditional offset designs ${ }^{21}$. Previous studies reporting improvements in hepatic flow distribution with the Y-graft design, compared to the traditional design, are in agreement with the present work ${ }^{22}$.

Despite prior technical success of the Y-graft Fontan in surgical studies, the evidence for implanting the $Y$-graft solely based on potential to improve energetics of the overall Fontan circulation remains minimal ${ }^{23,24}$. While, improvements to hepatic flow distribution are observed in simulation studies, individual surgical planning should be performed to maximize equal distribution to the pulmonary arteries. It remains unclear whether the increased technical difficulty of the Y-graft procedure is outweighed by the potential benefits of improved hepatic performance, especially in light of the relatively small fraction of Fontan patients who go on to develop arteriovenous malformations (AVMs). However, in certain cases such as patients with interrupted IVC, the Y-graft offers a promising method to reduce the incidence of AVMs, and recent surgical planning studies have demonstrated success in these cases $^{25,26}$.

Modeling simulations provide the opportunity to provide data currently unobtainable by other modalities with essentially no risk to patients. One limitation surrounding modeling is availability of clinical data to ensure validation. The multiscale models used herein have been validated previously using pre-operative clinical data $^{10,11,13,14,27}$. However, post-surgical data is rarely available and not available for this study. We have previously discussed the type of information required and demonstrate a successful post-surgical validation ${ }^{28}$.

\section{Conclusion}

This paper represents the first case series of patient-specific multiscale modeling of the Fontan procedure. Representations of the patients' pre-operative physiologies were used to tune the models to match clinical data. Despite noticeable local power loss differences, graft selection does not affect systemic pressure and flow rates or other clinically relevant quantities. However, geometric differences from graft selection or positioning can directly impact IVC flow split, and personalized surgical planning could be used to optimize hepatic flow distribution in these cases. 
medRxiv preprint doi: https://doi.org/10.1101/2021.10.03.21264033; this version posted October 4, 2021. The copyright holder for this preprint (which was not certified by peer review) is the author/funder, who has granted medRxiv a license to display the preprint in perpetuity.

All rights reserved. No reuse allowed without permission.

\section{List of Tables}

Table 1: Pre-operative demographics of the six patients used for the study.

Table 2: Pre-operative clinical parameters used for patient-specific tuning.

Table 3: Post-operative predictions. 
Table 1: Pre-operative demographics of the six patients used for the study

\begin{tabular}{|c|c|c|c|c|c|c|}
\hline $\begin{array}{c}\text { Patient } \\
\begin{array}{c}\text { Age Range* } \\
\text { (years) }\end{array}\end{array}$ & A & B & C & D & E & F \\
\hline BSA (m) & 0.62 & 0.59 & 0.61 & 0.53 & 0.61 & $1-5$ \\
\hline Diagnosis & PA with IVS & HLHS & HLHS & HLHS & PA + AVVR with AR & HLHS \\
\hline Stage 2 surgery & BDG & BDG & BDG & BDG & BDG & BDG \\
\hline \hline
\end{tabular}

*Precise age used for model construction cannot be provided since it contains identifying information BSA - body surface area; PA - pulmonary atresia; IVS - intact ventricular septum; HLHS - hypoplastic left heart syndrome; BDG - bi-directional Glenn; A/MS - aortic/mitral stenosis; A/MA - aortic/mitral atresia; PAS - pulmonary artery stenosis; AR aortic valve regurgitation; AVVR - atrioventricular valve regurgitation: 0 none, + trace, ++ mild, +++ moderate, ++++ severe; t.a. - tricuspid atresia. LSVC - left superior vena cava. 
Table 2: Pre-operative clinical parameters used for patient-specific tuning.

\begin{tabular}{|c|c|c|c|c|c|c|c|c|c|c|c|c|}
\hline \multirow[t]{2}{*}{ PATIENT } & \multicolumn{2}{|l|}{$\mathbf{A}$} & \multicolumn{2}{|l|}{ B } & \multicolumn{2}{|l|}{$\mathrm{C}$} & \multicolumn{2}{|l|}{ D } & \multicolumn{2}{|l|}{$\mathbf{E}$} & \multicolumn{2}{|l|}{$\mathbf{F}$} \\
\hline & CLINICAL & LPM & CLINICAL & LPM & CLINICAL & LPM & CLINICAL & LPM & CLINICAL & LPM & CLINICAL & LPM \\
\hline $\begin{array}{c}\text { AoFF } \\
\text { (L/min) }\end{array}$ & 2.82 & 2.86 & 2.8 & 2.8 & 2.29 & 2.29 & 2.04 & 2.09 & 2.74 & 2.76 & 2.83 & 2.81 \\
\hline $\begin{array}{c}\text { Qsvc } \\
(\mathrm{L} / \mathrm{min})\end{array}$ & 1.56 & 1.58 & 1.07 & 1.07 & 0.76 & 0.77 & 0.72 & 0.74 & 0.93 & 0.96 & 0.95 & 0.95 \\
\hline $\begin{array}{c}\text { Qivc } \\
(\mathrm{L} / \mathbf{m i n})\end{array}$ & 0.84 & 0.84 & 0.91 & 0.91 & 0.78 & 0.76 & 0.6 & 0.61 & 0.76 & 0.78 & 0.95 & 0.94 \\
\hline $\begin{array}{c}\text { Qcoll } \\
\text { (L/min) }\end{array}$ & 0.42 & 0.41 & 0.82 & 0.81 & 0.76 & 0.76 & 0.72 & 0.74 & 1.04 & 1.02 & 0.93 & 0.92 \\
\hline Qrpa/Qpa & 0.5 & 0.52 & 0.61 & 0.61 & 0.54 & 0.58 & 0.67 & 0.68 & 0.7 & 0.56 & 0.59 & 0.55 \\
\hline $\begin{array}{l}P \text { atrium } \\
(\mathrm{mmHg})\end{array}$ & 6 & 5.7 & 10 & 9.1 & 7 & 5.7 & 4 & 4.12 & 7 & 5.47 & 3 & 3.74 \\
\hline $\begin{array}{c}\text { Ppa } \\
\left({ }^{*} \text { Psve) }\right. \\
\text { (mmHg) }\end{array}$ & 11 & 10.1 & 11 & 10.8 & 10 & 8.5 & 10 & 9.74 & 13 & 11.46 & 10 & 9.99 \\
\hline $\begin{array}{c}\text { Pao } \\
(\mathbf{m m H g})\end{array}$ & 57 & 56.3 & 53 & 52.1 & 56 & 55.1 & 57 & 58.28 & 54 & 53.51 & 54 & 54.09 \\
\hline
\end{tabular}

AoFF - Aortic Forward Flow; Qsvc - Superior Vena Cava flow, Qivc - Inferior Vena Cava flow; Qcoll - collateral flow; Qrpa/Qpa - Ratio of right pulmonary artery flow to total pulmonary flow; P atrium - Atrial Pressure ; Ppa - Pulmonary Arterial pressure; Pao - Aortic pressure; 
Table 3: Post-operative predictions

\begin{tabular}{|c|c|c|c|c|c|c|c|c|c|c|}
\hline \multirow{2}{*}{$\begin{array}{c}\text { PATIENT } \\
\text { PROCEDURE }\end{array}$} & \multicolumn{4}{|c|}{$\mathbf{A}$} & \multicolumn{3}{|c|}{ B } & \multicolumn{3}{|c|}{ C } \\
\hline & Y 9mm & Y $12 \mathrm{~mm}$ & ECC & Y12 Alt & Y 9mm & Y $12 \mathrm{~mm}$ & ECC & Y $9 \mathrm{~mm}$ & Y $12 \mathrm{~mm}$ & ECC \\
\hline $\begin{array}{l}\text { AoFF } \\
(\mathrm{L} / \mathrm{min})\end{array}$ & 2.77 & 2.77 & 2.76 & 2.77 & 2.84 & 2.84 & 2.84 & 2.29 & 2.29 & 2.29 \\
\hline $\begin{array}{c}\text { Qsvc } \\
(\mathrm{L} / \mathrm{min})\end{array}$ & 1.6 & 1.61 & 1.58 & 1.61 & 1.11 & 1.11 & 1.11 & 0.78 & 0.78 & 0.78 \\
\hline Qive (L/min) & 0.72 & 0.72 & 0.75 & 0.72 & 0.86 & 0.86 & 0.87 & 0.72 & 0.72 & 0.72 \\
\hline Qcoll (L/min) & 0.45 & 0.44 & 0.43 & 0.44 & 0.87 & 0.87 & 0.87 & 0.79 & 0.79 & 0.8 \\
\hline Qrpa/Qpa & 0.51 & 0.52 & 0.51 & 0.51 & 0.62 & 0.62 & 0.62 & 0.54 & 0.54 & 0.53 \\
\hline $\begin{array}{c}P \text { atrium } \\
(\mathrm{mmHg})\end{array}$ & 3.02 & 3.04 & 3.01 & 3.03 & 7.1 & 7.11 & 7.12 & 3.18 & 3.18 & 3.17 \\
\hline $\begin{array}{l}\text { Ppa (*Psvc) } \\
\text { (mmHg) }\end{array}$ & $13.13^{*}$ & $13.15^{*}$ & $13.29 *$ & $13.16^{*}$ & $11.83^{*}$ & $11.89^{*}$ & $11.86^{*}$ & $8.83 *$ & $8.87 *$ & $8.98^{*}$ \\
\hline Pao (mmHg) & 57.42 & 57.48 & 57.47 & 57.45 & 53.13 & 53.15 & 53.14 & 55.24 & 55.26 & 55.26 \\
\hline $\begin{array}{l}\text { Power Loss } \\
\quad(\mathrm{mW})\end{array}$ & 5.87 & 5.53 & 6.32 & 5.76 & 7.71 & 7.6 & 7.05 & 3.43 & 3.36 & 3.59 \\
\hline $\begin{array}{l}\text { Pa-Sa Loss } \\
\quad(\mathrm{mW})\end{array}$ & 46.48 & 46.67 & 46.44 & 46.55 & 12.87 & 12.92 & 13.04 & 14.93 & 14.96 & 14.97 \\
\hline Total Pul Loss & 52.35 & 52.2 & 52.76 & 52.31 & 20.58 & 20.52 & 20.09 & 18.36 & 18.32 & 18.56 \\
\hline $\begin{array}{c}\text { IVC } \\
\text { Split } \quad \text { Left/All }\end{array}$ & 0.49 & 0.66 & 0.33 & 0.49 & 0.39 & 0.36 & 0.34 & 0.42 & 0.36 & 0.61 \\
\hline
\end{tabular}




\begin{tabular}{|c|c|c|c|c|c|c|c|c|c|}
\hline \multirow{2}{*}{$\begin{array}{c}\text { PATIENT } \\
\text { PROCEDURE }\end{array}$} & \multicolumn{3}{|c|}{ D } & \multicolumn{3}{|c|}{$\mathbf{E}$} & \multicolumn{3}{|c|}{$\mathbf{F}$} \\
\hline & Y 9mm & Y $12 \mathrm{~mm}$ & ECC & Y 9mm & Y $12 \mathrm{~mm}$ & ECC & Y 9mm & Y $12 \mathrm{~mm}$ & ECC \\
\hline $\begin{array}{c}\text { AoFF } \\
\text { (L/min) }\end{array}$ & 2.59 & 2.59 & 2.59 & 3.08 & 3.09 & 3.08 & 3.42 & 3.42 & 3.38 \\
\hline $\begin{array}{c}\text { Qsve } \\
\text { (L/min) }\end{array}$ & 0.88 & 0.88 & 0.88 & 1.05 & 1.02 & 1.02 & 1.16 & 1.16 & 1.15 \\
\hline Qive (L/min) & 0.63 & 0.63 & 0.63 & 0.82 & 0.86 & 0.85 & 1.04 & 1.05 & 1.02 \\
\hline Qcoll (L/min) & 1.08 & 1.08 & 1.08 & 1.21 & 1.21 & 1.22 & 1.21 & 1.21 & 1.21 \\
\hline Qrpa/Qpa & 0.61 & 0.61 & 0.6 & 0.66 & 0.66 & 0.66 & 0.57 & 0.56 & 0.59 \\
\hline $\begin{array}{l}P \text { atrium } \\
(\mathrm{mmHg})\end{array}$ & 5.64 & 5.66 & 5.62 & 6.94 & 6.95 & 6.91 & 3.74 & 3.76 & 3.52 \\
\hline $\begin{array}{c}\text { Ppa (*Psvc) } \\
(\mathrm{mmHg})\end{array}$ & $17.83 *$ & $17.82 *$ & $17.92 *$ & $18.7^{*}$ & $18.74 *$ & $18.86^{*}$ & $19.02 *$ & $19.06^{*}$ & $19.31 *$ \\
\hline Pao (mmHg) & 73.78 & 73.8 & 73.76 & 62.35 & 62.35 & 62.37 & 72.29 & 72.35 & 71.63 \\
\hline $\begin{array}{l}\text { Power Loss } \\
\quad(\mathrm{mW})\end{array}$ & 4.4 & 4.17 & 4.83 & 8.8 & 8.8 & 9.46 & 8.02 & 7.85 & 10.62 \\
\hline $\begin{array}{l}\text { Pa-Sa Loss } \\
\quad(\mathrm{mW})\end{array}$ & 35.03 & 35.11 & 34.9 & 36.34 & 36.33 & 36.19 & 62.54 & 62.66 & 61.28 \\
\hline Total Pul Loss & 39.43 & 39.28 & 39.73 & 45.14 & 45.13 & 45.65 & 70.56 & 70.51 & 71.9 \\
\hline $\begin{array}{c}\text { IVC } \\
\text { Split } \quad \text { Left/All } \\
\end{array}$ & 0.45 & 0.39 & 0.45 & 0.61 & 0.63 & 0.62 & 0.61 & 0.54 & 0.28 \\
\hline
\end{tabular}

AoFF - Aortic Forward Flow; Qsvc - Superior Vena Cava flow Qivc - Inferior Vena Cava flow; Qcoll - collateral flow; Qrpa/Qpa Ratio of right pulmonary artery flow to total pulmonary flow; P atrium - Atrial Pressure ; Ppa - Pulmonary Arterial pressure; Pao Aortic pressure 
medRxiv preprint doi: https://doi.org/10.1101/2021.10.03.21264033; this version posted October 4, 2021. The copyright holder for this preprint (which was not certified by peer review) is the author/funder, who has granted medRxiv a license to display the preprint in perpetuity.

All rights reserved. No reuse allowed without permission.

\section{List of Figures}

Figure 1. Pre-operative (stage 2) and virtual surgery (stage 3) anatomies for the six patients studied.

Figure 2: Multiscale simulation setup.

Figure 3: Time-averaged velocity and wall shear stress maps, and ventricular pressure-volume loops for GOSH30.

Figure 4. Maximum difference in the local power loss of the Fontan surgical junction between graft options relative to the total power loss in the pulmonary circulation (averaged across all graft option cases).

Figure 5: Mean and standard deviation of physiologic parameters compared between graft options, and p-values from one-way ANOVA. 

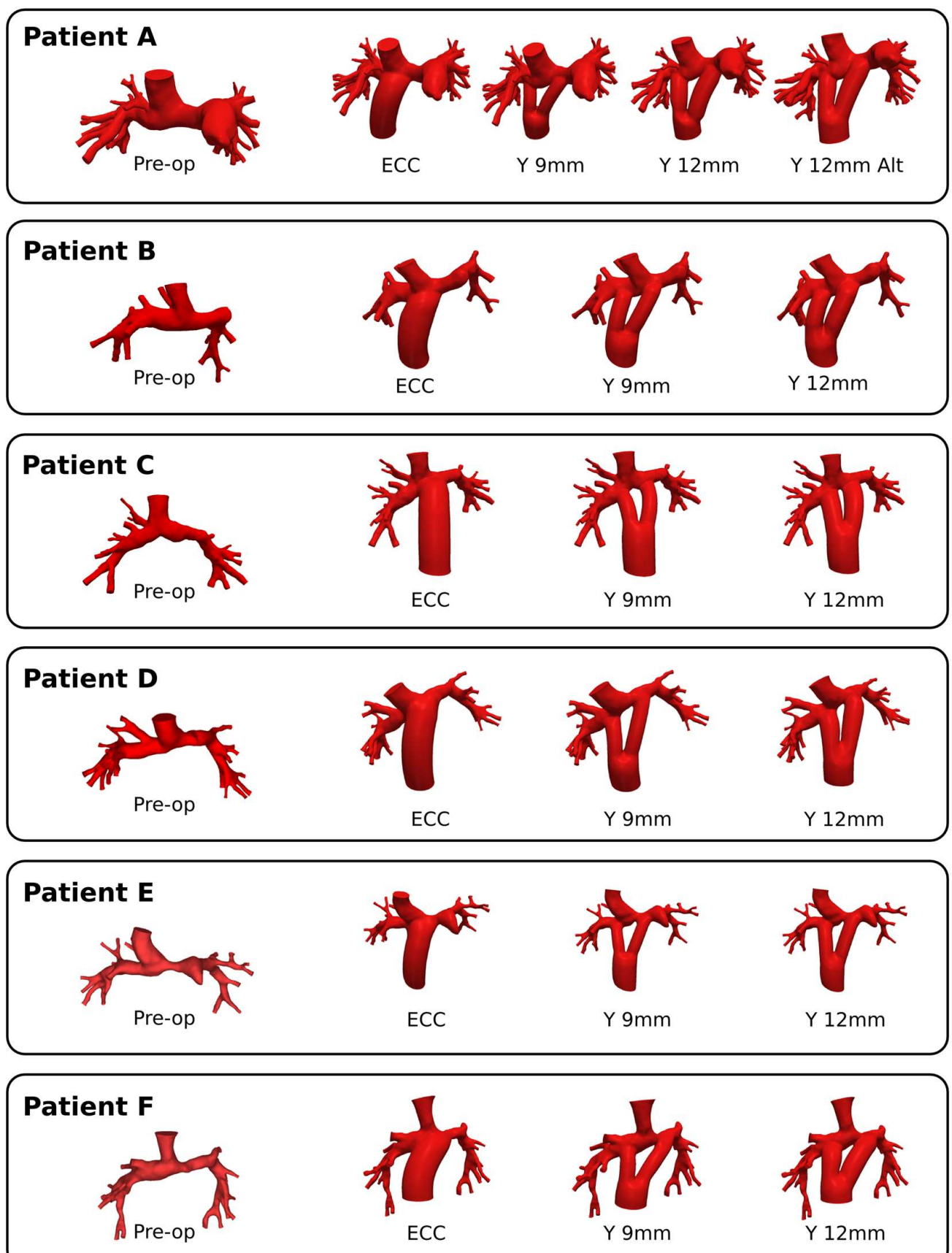

Figure 1: Pre-operative (stage 2) and virtual surgery (stage 3) anatomies for the six patients studied. 
medRxiv preprint doi: https://doi.org/10.1101/2021.10.03.21264033; this version posted October 4, 2021. The copyright holder for this preprint (which was not certified by peer review) is the author/funder, who has granted medRxiv a license to display the preprint in perpetuity. All rights reserved. No reuse allowed without permission.

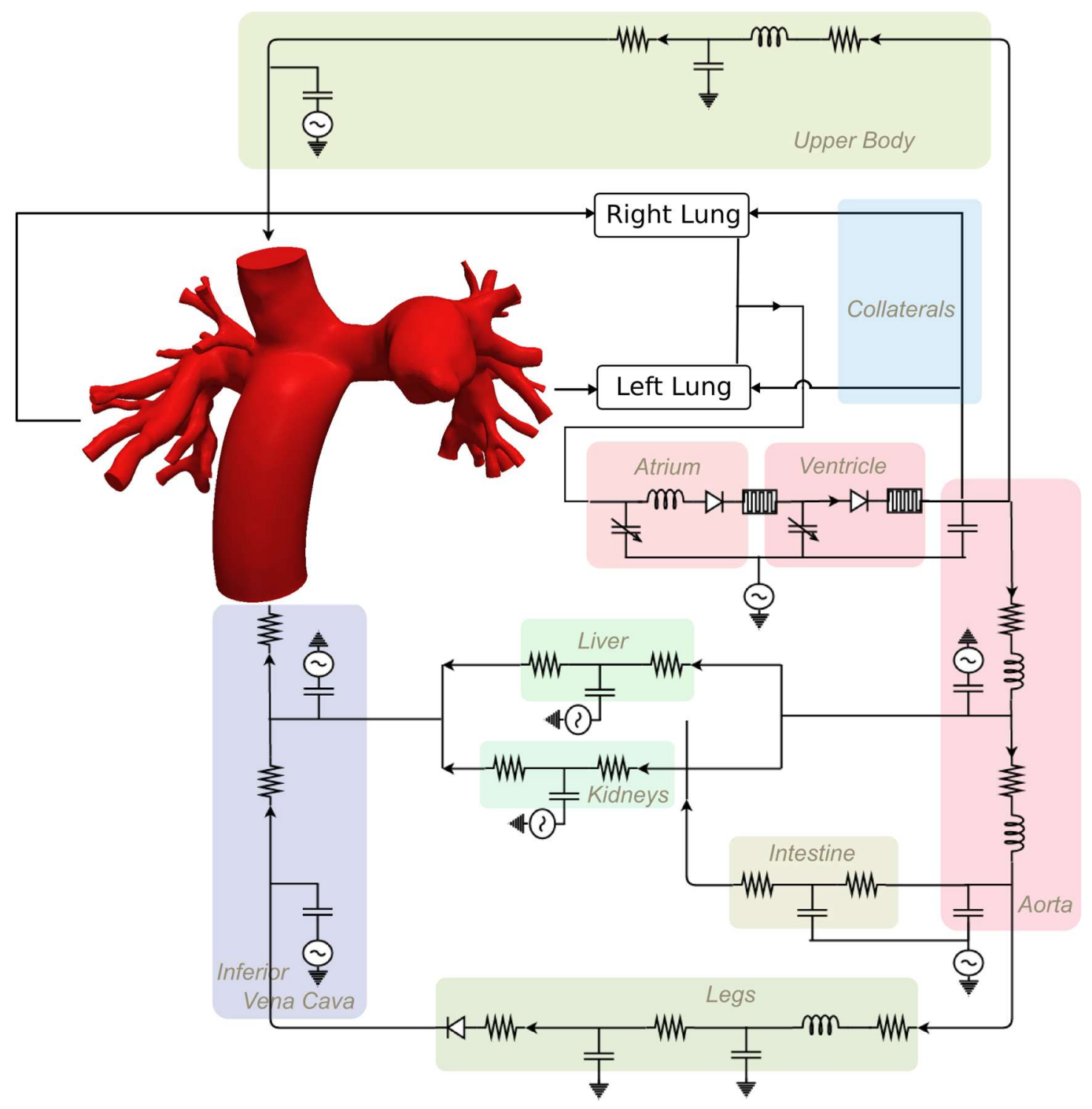

Figure 2: Postoperative multiscale simulation setup. 


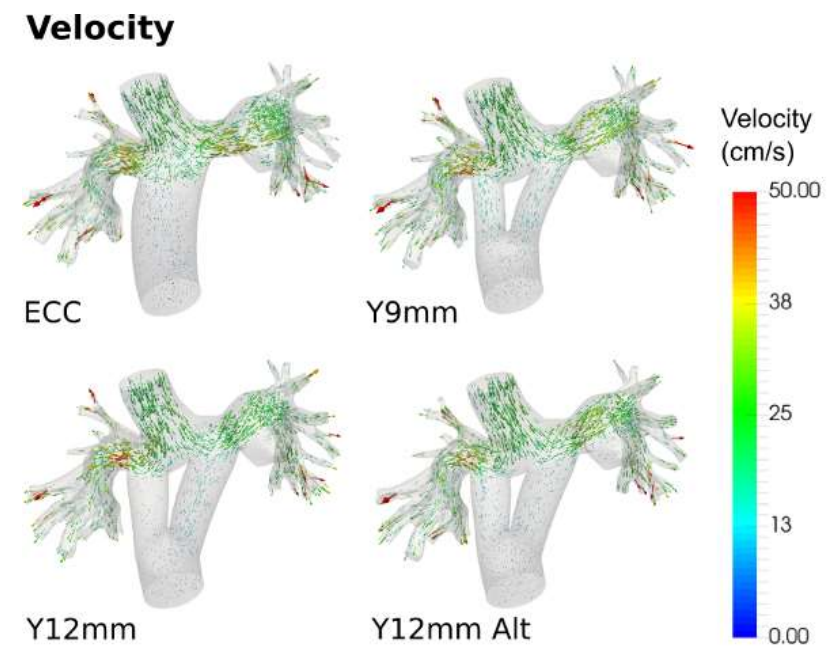

\section{Wall Shear Stress}
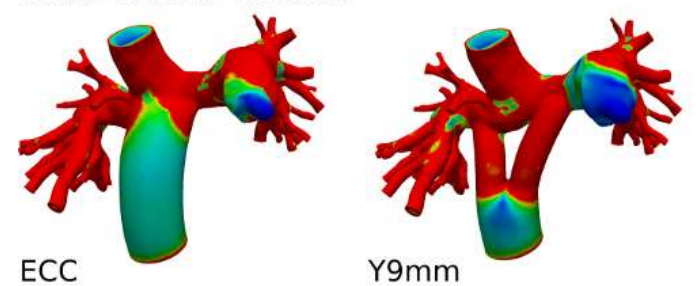

WSS

(dynes $/ \mathrm{cm}^{2}$ )
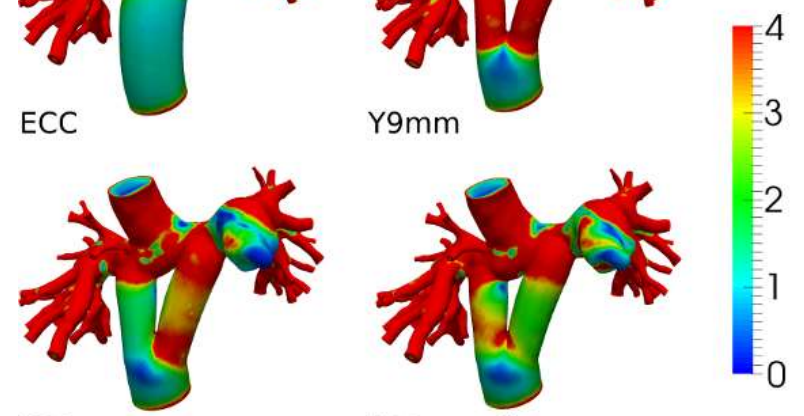

$\mathrm{Y} 12 \mathrm{~mm}$

Y12mm Alt

Ventricular Pressure-volume Loop
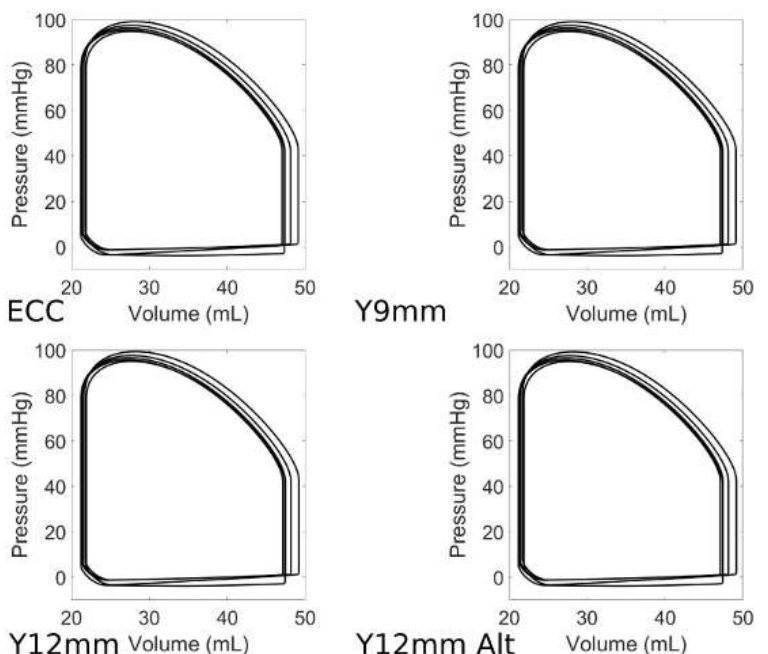

$\mathrm{Y} 9 \mathrm{~mm}$

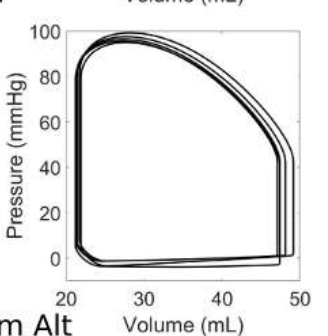

Figure 3: Time-averaged velocity and wall shear stress maps, and ventricular pressure-volume loops for GOSH30. 
medRxiv preprint doi: https://doi.org/10.1101/2021.10.03.21264033; this version posted October 4, 2021. The copyright holder for this preprint (which was not certified by peer review) is the author/funder, who has granted medRxiv a license to display the preprint in perpetuity.

All rights reserved. No reuse allowed without permission.

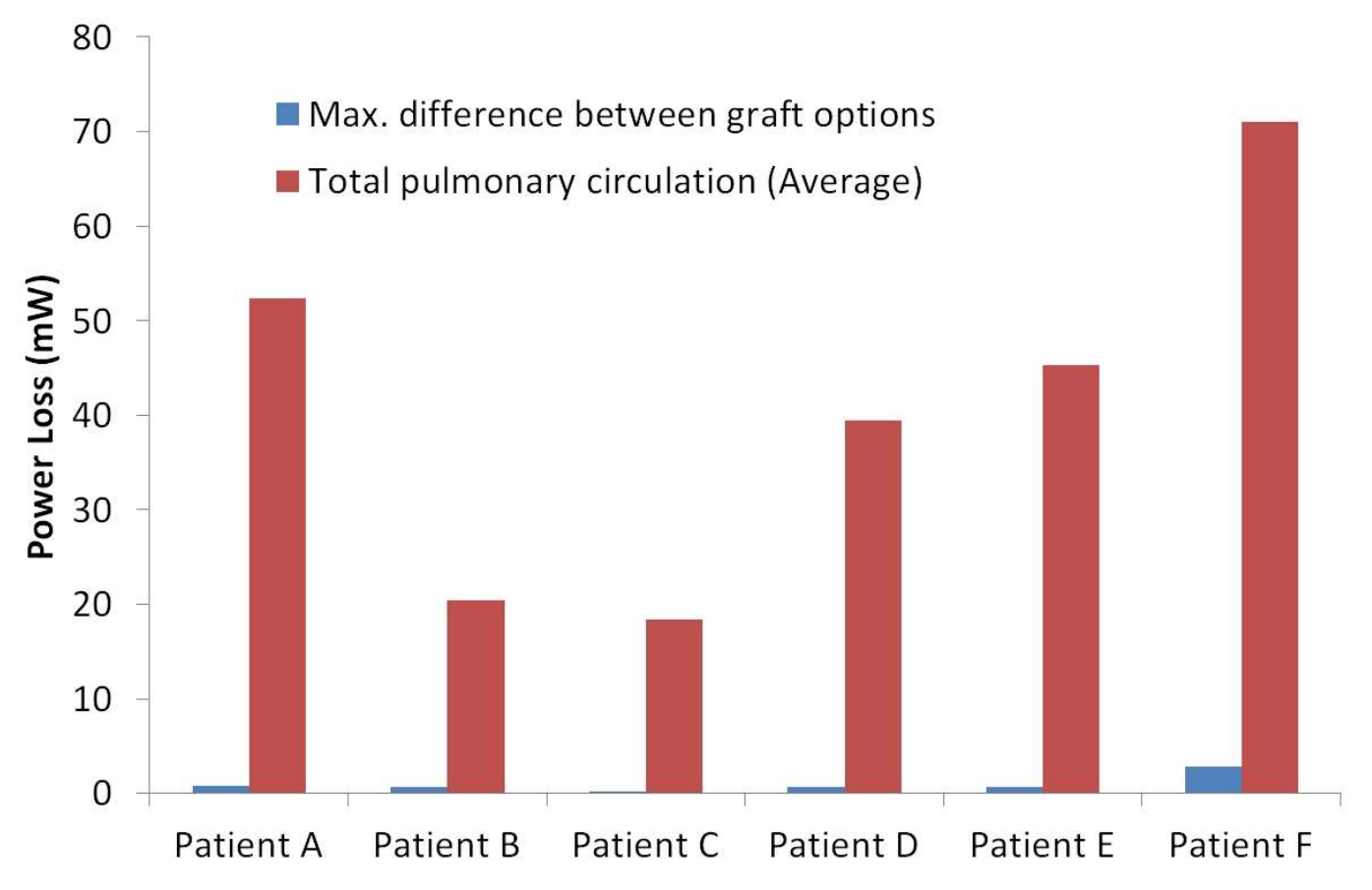

Figure 4: Maximum difference in the local power loss of the Fontan surgical junction between graft options relative to the total power loss in the pulmonary circulation (averaged across all graft option cases). 

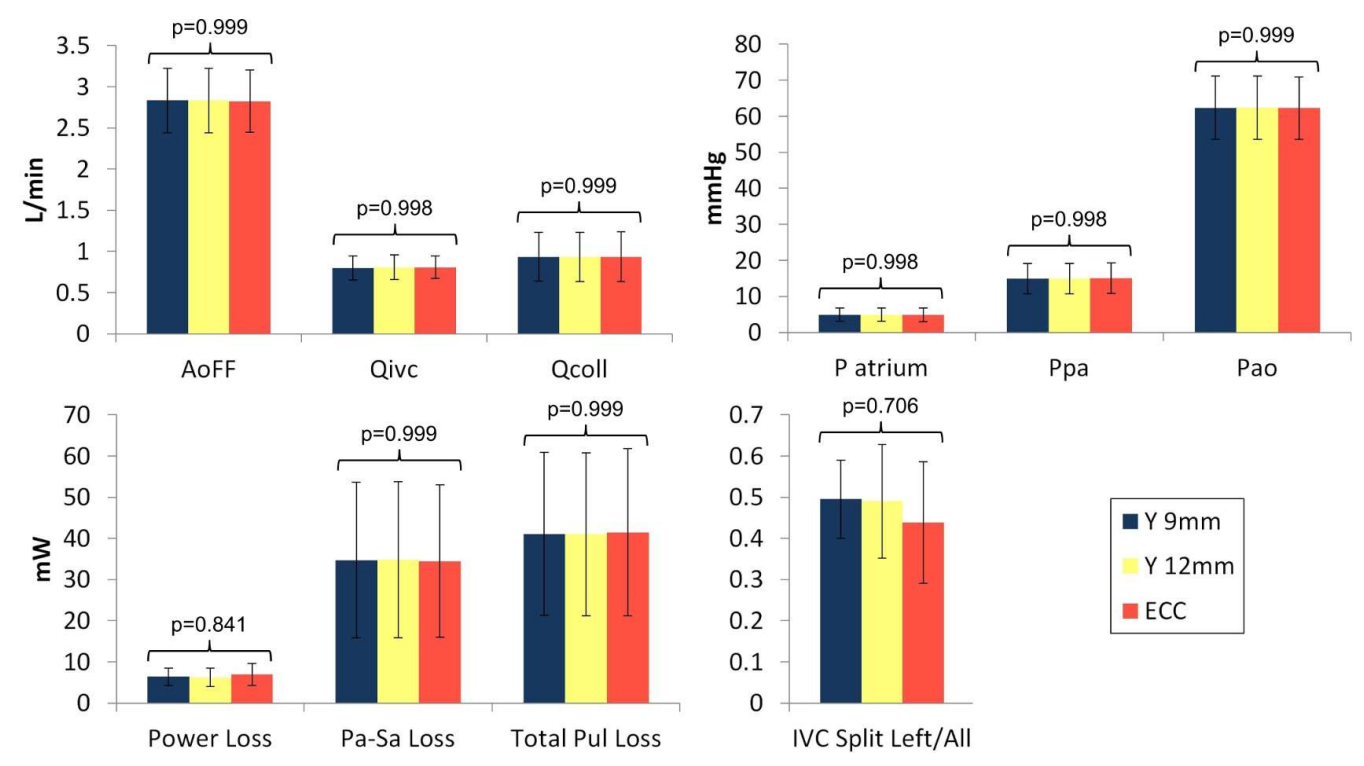

Figure 5: Mean and standard deviation of physiologic parameters compared between graft options, and p-values from one-way ANOVA.

AoFF - Aortic Forward Flow; Qivc - Inferior Vena Cava flow; Qcoll - collateral flow; P atrium - Atrial Pressure ; Ppa - Pulmonary Arterial pressure; Pao Aortic pressure 


\section{REFERENCES}

1. Gewillig M, Brown SC, Eyskens B, et al. The Fontan circulation: who controls cardiac output? Interactive Cardiovascular and Thoracic Surgery. 2010;10(3):428-433.

2. de Leval MR, Deanfield JE. Four decades of Fontan palliation. Nat Rev Cardiol. 2010;7(9):520-527.

3. Nir A, Driscoll DJ, Mottram CD, et al. Cardiorespiratory response to exercise after the Fontan operation: a serial study. J Am Coll Cardiol. 1993;22(1):216-220.

4. Gersony DR, Gersony WM. Management of the postoperative Fontan patient. Progress in Pediatric Cardiology.17(1):73-79.

5. McRae ME. Long-term issues after the Fontan procedure. AACN $A d v$ Crit Care. 2013;24(3):264-282; quiz 283-264.

6. Marsden AL, Bernstein AJ, Reddy VM, et al. Evaluation of a novel Yshaped extracardiac Fontan baffle using computational fluid dynamics. $J$ Thorac Cardiovasc Surg. 2009;137(2):394-403.e392.

7. Haggerty CM, Kanter KR, Restrepo M, et al. Simulating hemodynamics of the Fontan Y-graft based on patient-specific in vivo connections. $J$ Thorac Cardiovasc Surg. 2013;145(3):663-670.

8. Yang W, Feinstein JA, Shadden SC, Vignon-Clementel IE, Marsden AL. Optimization of a Y-graft design for improved hepatic flow distribution in the Fontan circulation. Journal of biomechanical engineering. 2013;135(1):011002.

9. Hsia TY. Taming the Fontan with the Y-graft: A nod and a wink to the great Yu. J Thorac Cardiovasc Surg. 2016;151(6):1537-1539.

10. Baker C, Kung E, Corsini C, et al. Hemodynamics After Second Stage Single Ventricle Palliation are Determined by Patient Characteristics Not Surgical Strategy: a Patient-Specific Multiscale Computational Study. JTCVS. submitted 2018.

11. Corsini C, Baker C, Kung E, et al. An integrated approach to patientspecific predictive modeling for single ventricle heart palliation. Comput Methods Biomech Biomed Engin. 2013.

12. Schievano S, Migliavacca F, Coats L, et al. Percutaneous pulmonary valve implantation based on rapid prototyping of right ventricular outflow tract and pulmonary trunk from MR data. Radiology. 2007;242(2):490-497.

13. Kung E, Baretta A, Baker $\mathrm{C}$, et al. Predictive modeling of the virtual Hemi-Fontan operation for second stage single ventricle palliation: Two patient-specific cases. J Biomech. 2013;46(2):423-429.

14. Arbia G, Corsini C, Baker C, Pennati G, Hsia TY, Vignon-Clementel IE. Pulmonary Hemodynamics Simulations Before Stage 2 Single Ventricle Surgery: Patient-Specific Parameter Identification and Clinical Data Assessment. Cardiovasc Eng Technol. 2015;6(3):268-280.

15. Baker CE, Corsini C, Cosentino D, et al. Effects of pulmonary artery banding and retrograde aortic arch obstruction on the hybrid palliation of hypoplastic left heart syndrome. J Thorac Cardiovasc Surg. 2013.

16. Hsia TY, Cosentino D, Corsini C, Pennati G, Dubini G, Migliavacca F. Use of mathematical modeling to compare and predict hemodynamic 
effects between hybrid and surgical Norwood palliations for hypoplastic left heart syndrome. Circulation. 2011;124(11 Suppl):S204-210.

17. Esmaily Moghadam M, Bazilevs Y, Hsia TY, Vignon-Clementel IE, Marsden AL. A comparison of outlet boundary treatments for prevention of backflow divergence with relevance to blood flow simulations. Computational Mechanics. 2011:1-15.

18. Baretta A, Corsini C, Yang W, et al. Virtual surgeries in patients with congenital heart disease: a multi-scale modelling test case. Philosophical Transactions of the Royal Society A: Mathematical, Physical and Engineering Sciences. 2011;369(1954):4316-4330.

19. Kung E, Baretta A, Baker C, et al. Predictive modeling of the virtual Hemi-Fontan operation for second stage single ventricle palliation: Two patient-specific cases. Journal of Biomechanics. 2013;46(2):423-429.

20. Yang W, Feinstein JA, Marsden AL. Constrained optimization of an idealized $\mathrm{Y}$-shaped baffle for the Fontan surgery at rest and exercise. Computer Methods in Applied Mechanics and Engineering. 2010;199(33):2135-2149.

21. Restrepo M, Luffel M, Sebring J, et al. Surgical planning of the total cavopulmonary connection: robustness analysis. Ann Biomed Eng. 2015;43(6):1321-1334.

22. Yang W, Vignon-Clementel IE, Troianowski G, Reddy VM, Feinstein JA, Marsden AL. Hepatic blood flow distribution and performance in conventional and novel Y-graft Fontan geometries: A case series computational fluid dynamics study. J Thorac Cardiovasc Surg. 2011.

23. Martin MH, Feinstein JA, Chan FP, Marsden AL, Yang W, Reddy VM. Technical feasibility and intermediate outcomes of using a handcrafted, area-preserving, bifurcated Y-graft modification of the Fontan procedure. J Thorac Cardiovasc Surg. 2015;149(1):239-245.e231.

24. Yang W, Chan FP, Reddy VM, Marsden AL, Feinstein JA. Flow simulations and validation for the first cohort of patients undergoing the Y-graft Fontan procedure. J Thorac Cardiovasc Surg. 2015;149(1):247255.

25. Kanter KR. Alternative Techniques for the Fontan Operation. Operative Techniques in Thoracic and Cardiovascular Surgery.19(1):64-79.

26. Kanter KR, Haggerty CM, Restrepo $M$, et al. Preliminary clinical experience with a bifurcated Y-graft Fontan procedure--a feasibility study. J Thorac Cardiovasc Surg. 2012;144(2):383-389.

27. Corsini C, Baker C, Baretta A, et al. Integration of Clinical Data Collected at Different Times for Virtual Surgery in Single Ventricle Patients: A Case Study. Ann Biomed Eng. 2014.

28. Vignon-Clementel IE, Marsden AL, Feinstein JA. A primer on computational simulation in congenital heart disease for the clinician. Progress in Pediatric Cardiology. 2010;30(1):3-13. 